\title{
Easy Kinetics: a novel enzyme kinetic characterization software
}

\author{
Gabriele Morabito ${ }^{1,2} *$ \\ 1 Department of Biology, University of Pisa, Pisa, Italy \\ 2 Max Planck Institute for Biology of Ageing, Cologne, Germany
}

\author{
Keywords: computational enzymology, enzyme's kinetic \\ doi: $10.5281 /$ zenodo.3242785
}

\begin{abstract}
Here will be presented the software Easy Kinetics, a publicly available graphical interface that allows rapid evaluation of the main kinetics parameters in an enzyme catalyzed reaction. In contrast to other similar commercial software using algorithms based on non-linear regression models to reach these results, Easy Kinetics is based on a completely different original algorithm, requiring in input the spectrophotometric measurements of $\Delta \mathrm{Abs} / \mathrm{min}$ taken twice at only two different substrate concentrations. The results generated show however a significant concordance with those ones obtained with the most common commercial software used for enzyme kinetics characterization, GraphPad Prism 8@ [1], suggesting that Easy Kinetics can be used for routine tests in enzyme kinetics as an alternative valid software.
\end{abstract}

\section{Introduction}

The continuous and rapid evolution of modern biochemical methods make the study of enzyme's kinetic very useful both in academic research, to test how interesting polypeptidic chain's variation impact on enzymes functionality, and in industrial processes, to optimize the production processes of the molecules of interest in enzymatic reactors [2]. The Michaelis-Mentem reaction mechanism was proposed almost a century ago to describe how the reaction speed of enzymes is affected by the substrate's concentration [3], and it's still the core reference model to describe enzymes kinetics. This model however requires a few parameters to fit the raw data: $n H, \mathrm{~K}_{\mathrm{m}}$ and $\mathrm{V}_{\max }$. Several methods were developed by biochemists during years to evaluate these parameters from the raw data, the most used of which allow software like GraphPad Prism 8@ [1] to apply linear or non-linear regression model [4]. Original alternative methods for $K_{m}$ and $V_{\max }$ determination were proposed, which graphically determine these values [5], but like the previous ones they require multiple spectrophotometric measurements of $\Delta \mathrm{Abs} / \mathrm{min}$ (at least 6 conducted in duplicate) at different substrate concentrations to precisely determine the main kinetic parameters. In this paper will be presented an alternative method implemented in the software Easy Kinetics, which allows determination of the main kinetics parameters of an enzyme catalyzed reaction and the corresponding kinetics graphs, by the spectrophotometric measurements of $\Delta \mathrm{Abs} / \mathrm{min}$ taken twice at only two different substrate concentrations.

\section{Materials and methods}

\section{Algorithm used in evaluation of $K_{m}$ and $V_{\max }$ :}

The evaluation of $\mathrm{K}_{\mathrm{m}}$ and $\mathrm{V}_{\max }$ by the spectrophotometric measurements of $\Delta \mathrm{Abs} / \mathrm{min}$ taken twice at only two different substrate concentrations, is based on a trigonometric demonstration (Fig.1). Briefly the algorithm transforms the mean of the duplicates at the two measurements in their reciprocal values, considering the Lineweaver-Burk reciprocal plot. Known two points of this graph, it's universally accepted that they can be joined by one and only one straight line. This line will have an unknown inclination "a" and will intersect the Cartesian axes in points $\frac{1}{V_{\max }}$ and $-\frac{1}{K_{m}}$, also unknown. However by tracing the projections of the two known 
points $\left(x_{1}, y_{1}\right)$ and $\left(x_{2}, y_{2}\right)$ on the Cartesian plane, it is evident that the parallel lines $y=y_{2}$ and $y=0$ intersect the studied straight line. By the Alternate Interior Angles theorem [6], if two parallel lines are cut by a transversal one, then the pairs of alternate interior angles are congruent: so, by Fig.1, "a" = "a $a$. Considering instead the lines $y=y_{2}$ and $y=y_{1}$, which are also parallel and intersected by the studied straight line, for the same theorem discussed before, their internal alternate angles are congruent: so, by Fig.1, " $a_{1} "=$ " $a_{2} "$. This implies that:

$$
\tan (a)=\frac{y_{2}-y_{1}}{x_{2}-x_{1}}
$$

But also $\frac{z}{x_{2}}=\tan (a)$, with $z=y_{2}-\frac{1}{V_{\max }}$, so:

$$
\frac{1}{V_{\max }}=y_{2}-\mathrm{z}=y_{2}-\left(\tan (a) * x_{2}\right)=y_{2}-\frac{x_{2} *\left(y_{2}-y_{1}\right)}{x_{2}-x_{1}}
$$

Once calculated $\frac{1}{V_{\max }}$, the value of $\frac{1}{K_{m}}$ can be determined as follow:

$$
\left|-\frac{1}{K_{m}}\right|=\frac{\frac{1}{V_{\max }}}{\tan (a)}
$$

Inverting the two values $K_{m}$ and $V_{\max }$ are finally found and from there by subsequent biochemical relations the other kinetic parameters are deduced (Supplementary material) [8-11].

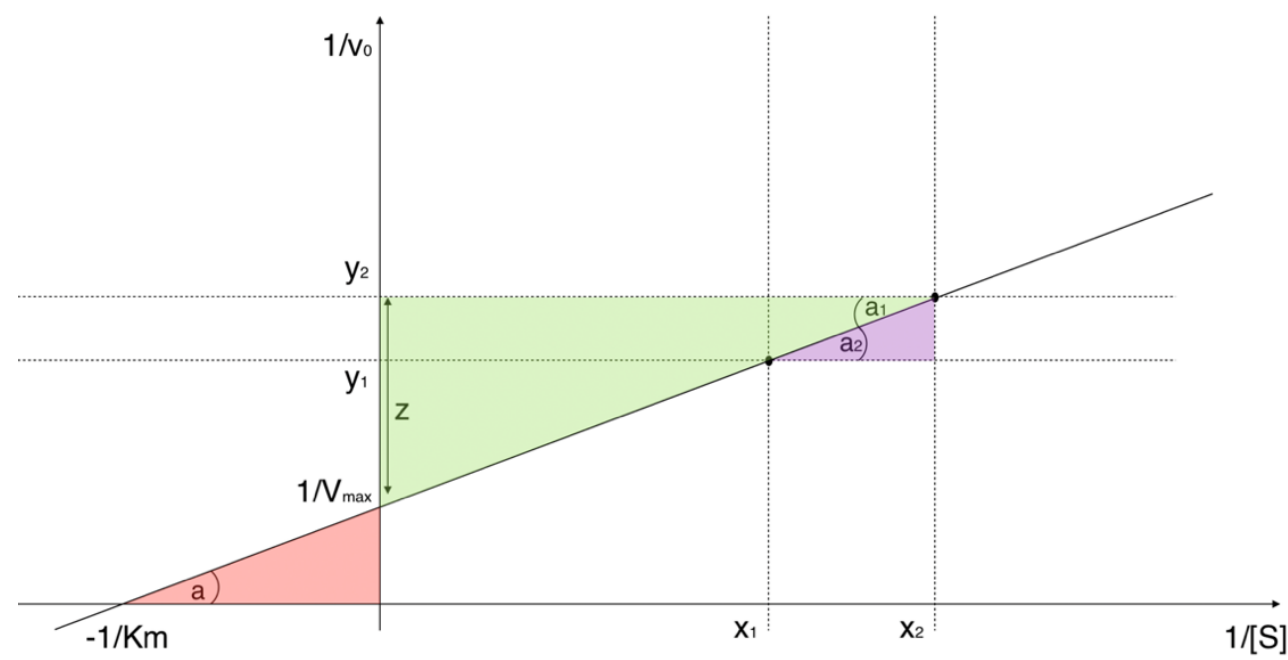

Fig 1. Graphical trigonometric demonstration of the $K_{m}$ and $V_{\max }$ evaluation based on Lineweaver-Burk reciprocal plot

Since Easy Kinetics receives in input only two spectrophotometric measurements, despite being performed twice, if one of these measures is anomalous, it won't be corrected by other measurements as occurs with regression models; so the software may fall in error. Thus to minimize experimental bias the algorithm is implemented to consider the $\Delta \mathrm{Abs} / \mathrm{min}$ at one substrate concentration only if both the duplicates fall within the range of their mean $\pm 10 \%$ of their average, otherwise the software suggest to repeat these measurements for the substrate concentration considered.

\section{Software implementation and distribution:}

Easy Kinetics was developed in C\# language with a GPL-3.0 license, both for the versatility of C\# and the design object-oriented, for Windows 10 environment (with October update installed), because of the diffusion 
bioRxiv preprint doi: https://doi.org/10.1101/674051; this version posted April 15, 2020. The copyright holder for this preprint (which was not certified by peer review) is the author/funder, who has granted bioRxiv a license to display the preprint in perpetuity. It is made available under aCC-BY 4.0 International license.

of Windows 10 and the consequent ease of software distribution. The software installation package can be downloaded freely as windows application on Microsoft Store at the URL:https://www.microsoft.com/itit/p/easy-kinetics/9nx1f4q5fpg5?activetab=pivot:overviewtab) or alternatively on the repository GitHub (DOI: 10.5281/zenodo.3242785) at the URL:https://github.com/ekin96/EasyKinetics. Easy Kinetics allows the user to operate in 5 different environments several kinetics analyses: "Simple Enzyme Kinetics", "Inhibition Kinetics", "Enzymatic Units Assay", "Calculation of $\Delta \mathrm{Abs} / \mathrm{min}$ ", "Bradford Assay". Furthermore Easy Kinetics was optimized to self-detect possible substrate-inhibition kinetics.

\section{Statistical analysis:}

All statistical analyses were conducted in the software R (v 3.6.1) [12], using both Easy Kinetics and GraphPad Prism 8 [1] for the kinetic analyses. Detailed statistics for all the experiments can be found in the figure legends and/or in the manuscript together with the $n$ and definitions of center and dispersion. In all figures, $n$ represents the number of different substrates that were used. Before using the Pearson's or Spearman's correlation test and using C.V. or Q.C.V. as error value, normality of the variables was checked using the Shapiro-Wilk normality test. Statistical significance was defined for $p<0.05$ in all comparisons and calculated as described in the manuscript and/or figure legends.

\section{Results}

\section{Software interface:}

Easy kinetics provides to users 5 different user-friendly working environment, "Enzymatic Units Assay" and "Bradford Assay" can both be used alone or included inside "Simple Enzyme Kinetics", which represent the main environment of the software (Fig.3). Both the "Simple Enzyme Kinetics" and "Inhibition Kinetics" environment allow users to generate basal kinetic graphs based on the kinetic parameters evaluated.

\section{Kinetic parameters generated with Easy Kinetics shows high accuracy and concordance with those ones generated by GraphPad Prism 8:}

In order to show Easy Kinetics accuracy in the evaluation of the main kinetic parameter, several time series absorbances were acquired for the enzymes aldehyde dehydrogenase and xanthine oxidase at different concentrations of several limiting substrates for the reaction they catalyzed (Fig.2A). Then for each enzyme and each substrate the main kinetic parameters $n H, \mathrm{~K}_{\mathrm{m}}$ and $\mathrm{V}_{\max }$ were generated using Easy Kinetics "Simple Enzyme Kinetics" environment and every two points non repeated permutation of the raw data. In this way it was possible to evaluate the precision of the previous parameters generated by the software as (1-C.V.)*100 for $\mathrm{K}_{\mathrm{m}}$ and $n H$, showing a normal distribution of values generated for all the tested substrates, and as (1Q.C.V.) ${ }^{*} 100$ for $V_{\max }$, showing a non normal distribution of the values generated for 3 of the tested substrates (Fig.2E). In summary the parameters generated show very good precision values for $\mathrm{V}_{\max }(\sim 90 \%)$ and $n H$ $(100 \%)$ in all the reaction models, while a little less for $\mathrm{K}_{\mathrm{m}}(\sim 78 \%)$. Afterward the means values of $\mathrm{K}_{\mathrm{m}}$ and medians values of $V_{\max }$ generated by Easy Kinetics for all the tested substrates were correlated with those ones generated by GraphPad Prism 8@ [1] using the same input raw data (Fig.2F-G). The correlation analysis shows a significant Pearson's linear correlation coefficient of 0.99 for $\mathrm{V}_{\max }(\mathrm{t}=10.053$, df $=2$, $\mathrm{p}$-value $=$ $0.00975)$, with normally distributed values in both Easy Kinetics $(W=0.87392, p$-value $=0.3133)$ and GraphPad Prism 8@ $(\mathrm{W}=0.88607, \mathrm{p}$-value $=0.3652)$ evaluations, and a significant Spearman correlation coefficient of 1 for $\mathrm{K}_{\mathrm{m}}(\mathrm{S}=0$, $\mathrm{p}$-value $=0.08333)$, with non normally distributed values in both Easy Kinetics $(\mathrm{W}=0.67175, \mathrm{p}$-value $=0.005173)$ and GraphPad Prism $8 \odot(\mathrm{W}=0.65386, \mathrm{p}$-value $=0.002921)$ evaluations 
bioRxiv preprint doi: https://doi. org/10.1101/674051; this version posted April 15, 2020. The copyright holder for this preprint (which was not certified by peer review) is the author/funder, who has granted bioRxiv a license to display the preprint in perpetuity. It is made available under aCC-BY 4.0 International license.

A)
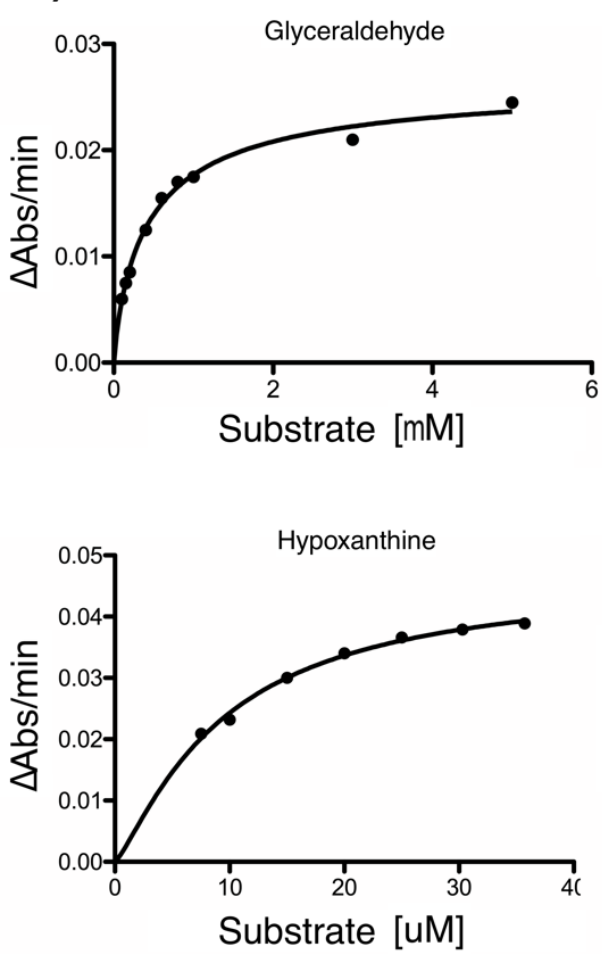

B)

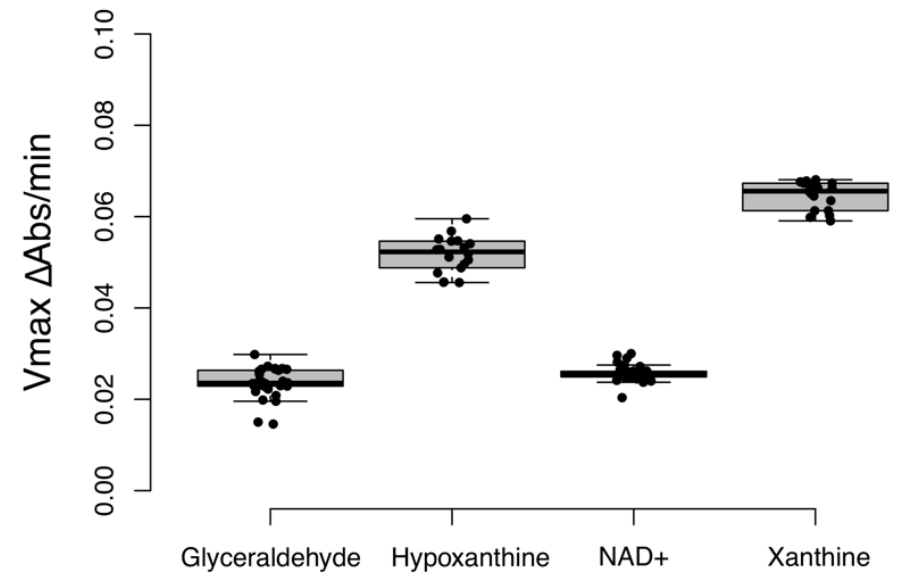

Substrate
F)
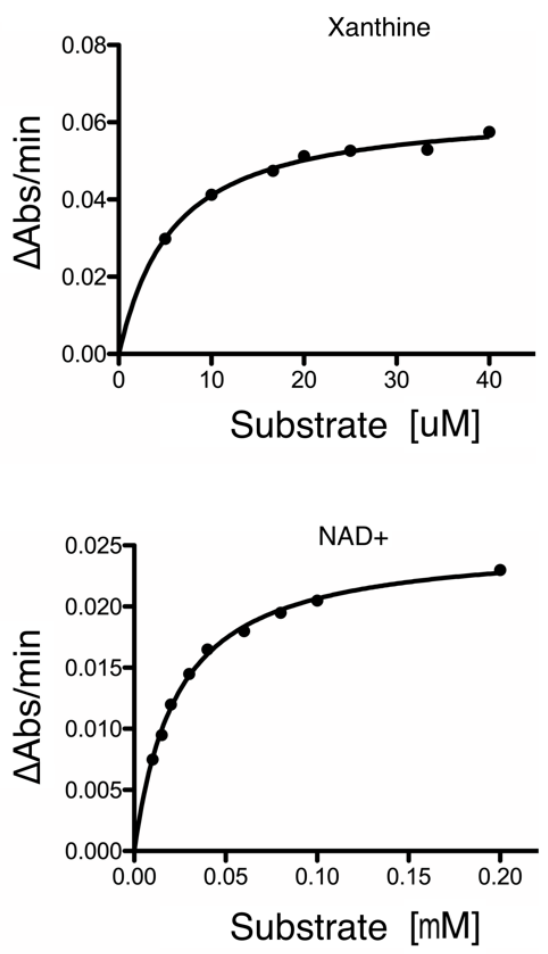

D)

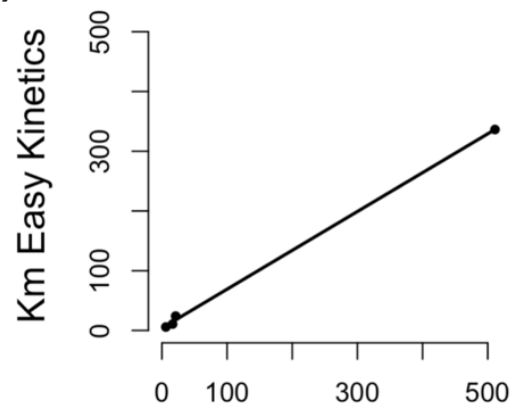

Km Graphpad Prism 8

G)

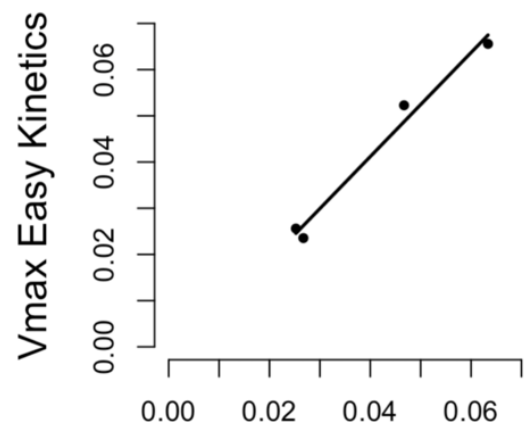

Vmax Graphpad Prism 8

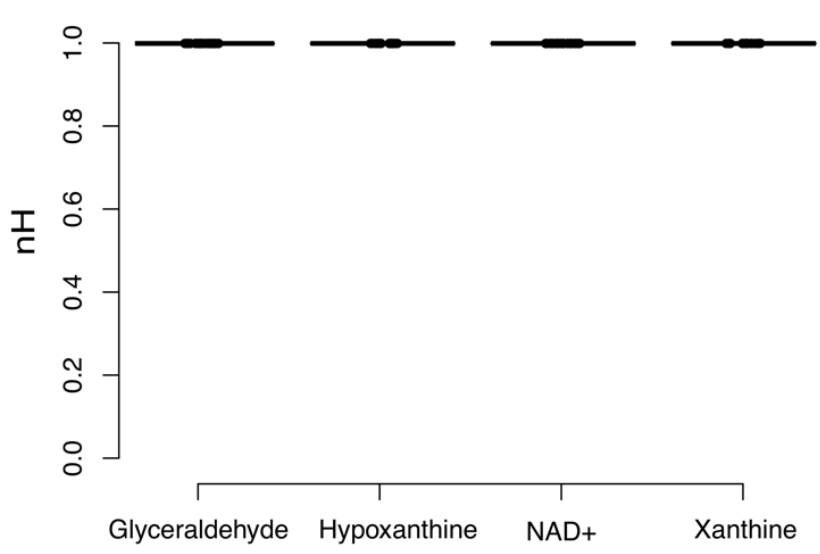

Substrate

E)

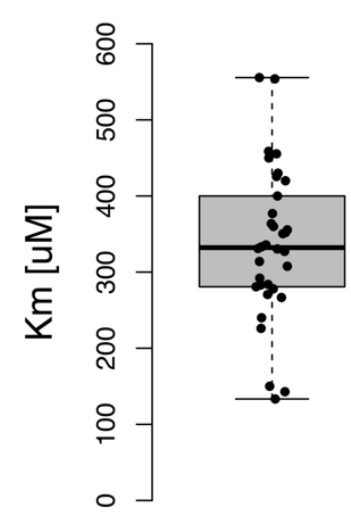

Glyceraldehyde

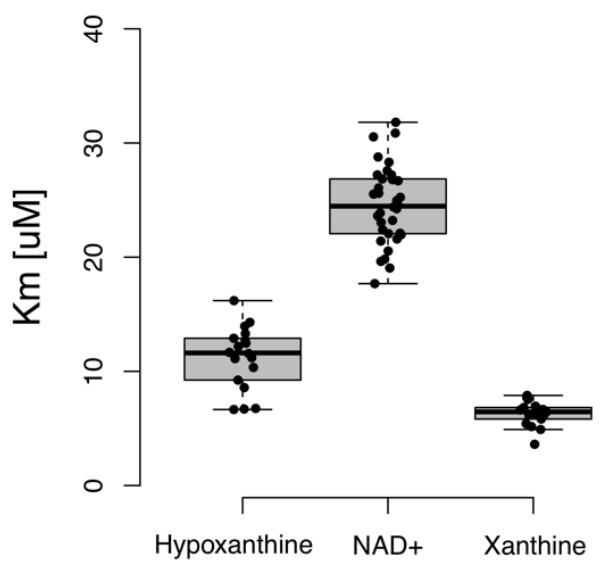

Substrate

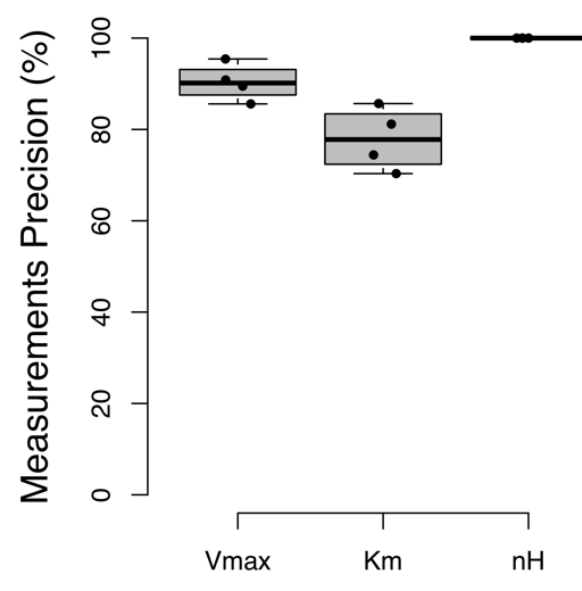

Parameter Considered

Fig.2 A) Kinetic curves of the two enzymes tested for different limiting substrates, respectively Xanthine or Hypoxanthine for Xanthine 
bioRxiv preprint doi: https://doi.org/10.1101/674051; this version posted April 15, 2020. The copyright holder for this preprint (which was not certified by peer review) is the author/funder, who has granted bioRxiv a license to display the preprint in perpetuity. It is made available under aCC-BY 4.0 International license.

oxidase and NAD+ or Glyceraldehyde for Aldehyde dehydrogenase, all the curves were generated using GraphPad Prism 8. B-D) Boxplots representing the distributions of $\mathrm{Vmax}, \mathrm{Km}$ and $\mathrm{nH}$ values generated with Easy Kinetics using every two points non repeated permutation of the raw data experimentally obtained. Glyceraldehyde values show a normal distribution for $\mathrm{Km}(\mathrm{W}=0.96956, \mathrm{p}$-value $=0.4494)$ and $\mathrm{nH}$, while a non normal distribution for $\operatorname{Vmax}(\mathrm{W}=0.89738$, $\mathrm{p}$-value $=0.003915)$. Hypoxanthine values show a normal distribution for $\operatorname{Vmax}(\mathrm{W}=0.96286, \mathrm{p}$-value $=0.6576), \mathrm{Km}(\mathrm{W}=0.94657, \mathrm{p}$-value $=0.3738)$ and $\mathrm{nH}$. $\mathrm{NAD}+$ values show a normal distribution for $\mathrm{Km}(\mathrm{W}$ $=0.98863$, $p$-value $=0.9728)$ and $\mathrm{nH}$, while a non normal distribution for $\operatorname{Vmax}(\mathrm{W}=0.90018, \mathrm{p}$-value $=0.004639)$. Xanthine values show a normal distribution for $\mathrm{Km}(\mathrm{W}=0.95116$, $\mathrm{p}$-value $=0.4751)$ and $\mathrm{nH}$, while a non normal distribution for $\mathrm{Vmax}(\mathrm{W}=0.88084$, $\mathrm{p}$-value $=$ 0.03281 ). Values outliers in position: 1,7,8,33,38,40,42,51,78,87,105 of the two point non repeated permutations dataset were eliminated for differing too much in Vmax and/or Km estimation from the central value of the distribution. E) Boxplots representing the precision of Vmax, $\mathrm{Km}$ and $\mathrm{nH}$ distribution central value for all the enzymes and limiting substrate tested $(\mathrm{n}=4)$, since $\mathrm{Km}$ and $\mathrm{nH}$ show a normal distribution of values for all the tested substrates, the precision of the estimation was calculated as (1-C.V.)* 100 , while for Vmax showing non normal distribution for 3 of the tested substrates, the precision was calculated as (1-Q.C.V.)*100. C.V. refers to the coefficient of variation while Q.C.V. to the quartile based coefficient of variation. F-G) scatterplots showing graphically the linear correlation between the Vmax and Km generated both by Easy Kinetics $(n=4)$ and GraphPad prism $8(n=4)$. The tested substrates show a normal distributions of medians values for Vmax generated using Easy Kinetics $(\mathrm{W}=0.87392$, $\mathrm{p}$-value $=0.3133$ ) and of values generated using GraphPad Prism8 ( $\mathrm{W}=0.88607, \mathrm{p}$-value $=0.3652$ ), allowing use of Pearson's linear correlation test, while a non normal distribution of mean values for Km generated using Easy Kinetics $(\mathrm{W}=0.67175$, $p$-value $=0.005173)$ and of values generated using GraphPad Prism8 $(\mathrm{W}=0.65386$, $\mathrm{p}$-value $=0.002921$ ), allowing use of Spearman's correlation test.

Surprisingly $n H$ values generated for all the substrates tested by Easy Kinetics show a standard deviation $\delta=$ 0 around a mean of 1 don't allowing any correlation test with the corresponding $n H$ values generated by GraphPad Prism 8 [1]. Thus for every substrate tested it was evaluated the ratios between GraphPad 8 and Easy Kinetics generated $n H$ ( 0.846 for Glyceraldehyde, 1.249 for Hypoxanthine, 1.024 for NAD+ and 1.045 for Xanthine), showing a mean value of 1.041 with a standard error of se $=0.083$ of the ratios normal distribution $(\mathrm{W}=0.96402$, $\mathrm{p}$-value $=0.8042)$.

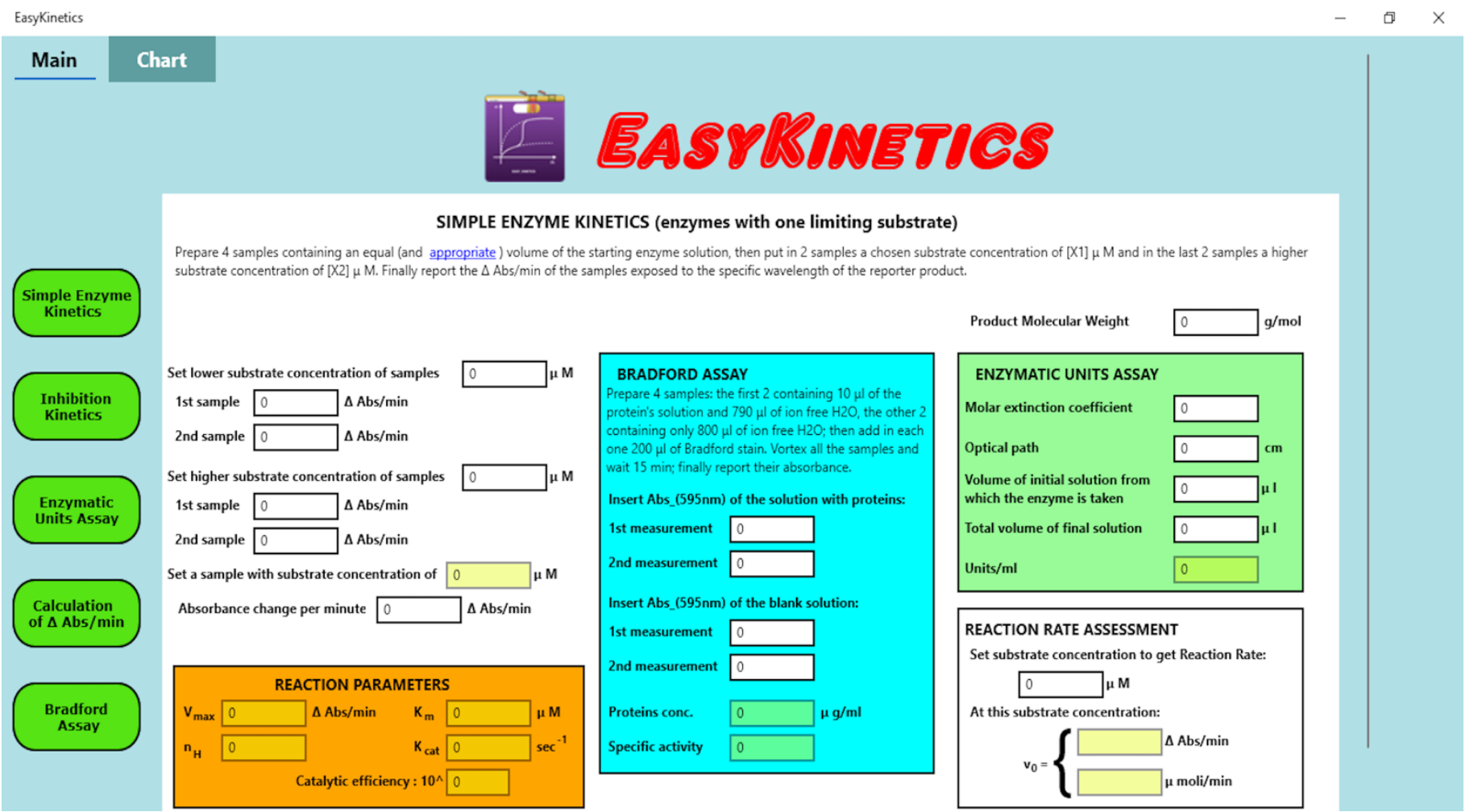

Fig.3 "Simple Enzyme Kinetics" environment, the input fields are characterized by a white background while the output fields by a colored one. On the left are listed the 5 software's environments while the top's buttons switch to and from the charts created using the parameters evaluated. Below the title of each environment there is a brief guideline to follow to assure the success of the experiment. 
bioRxiv preprint doi: https://doi.org/10.1101/674051; this version posted April 15, 2020. The copyright holder for this preprint (which was not certified by peer review) is the author/funder, who has granted bioRxiv a license to display the preprint in perpetuity. It is made available under aCC-BY 4.0 International license.

\section{Discussion}

The development of Easy Kinetics was driven by the need to have a publicly available graphical interface software, completely dedicated to perform basic enzyme's kinetic analyses as an alternative to available commercial software. Testing the kinetics of two enzymes for several limiting substrates has shown that the evaluation of the basic kinetic parameters $\mathrm{V}_{\max }, \mathrm{K}_{\mathrm{m}}$ and $n H$, from which the other parameters could be generated, gives significantly correlated values, or as regards to $n H$ almost the same value, both using several two points non repeated permutations in Easy Kinetics as well as the regression based model in GraphPad Prism 8 [1]. In addition it was shown that every permutation for the same substrate gives in output a parameter values with a precision of $\sim 90 \%$ for $\mathrm{V}_{\max }, 100 \%$ for $n \mathrm{H}$ and $\sim 78 \%$ for $\mathrm{K}_{\mathrm{m}}$ using Easy Kinetics environment. These results suggest Easy Kinetics could be used as a valid alternative of the most used commercial software for enzyme's kinetic analyses GraphPad prism 8 [1], with the advantages it could go deep in the kinetic analysis evaluating other important parameters like: $\mathrm{K}_{\text {cat }}$, catalytic efficiency or the specific activity of the enzyme, and it's freely available on public repositories. In addition Easy Kinetics original algorithm for the evaluation of $K_{m}$ and $V_{\max }$ tries to be an interesting alternative of usually used regression models, known to have several limitations [7].

\section{Conclusion}

Here it was presented a novel intuitive freely available software, completely dedicated to perform enzymatic kinetic characterizations and based on an original algorithm alternative to the common regression models used by commercial software to evaluate the main kinetic parameters of an enzyme. Requiring less input information than other commercial software like GraphPad Prism 8 [1], Easy Kinetics gives the chance to save time and money during enzyme's characterization experiments, in addition it allows researchers to go deep in this characterization evaluating several important parameters extremely useful to biochemists. However there are still computational improvements and graphical features achievable that are under development and will be reached in next software releases.

\section{Acknowledgments}

The author declares no conflicts of interests. No funding from any public or private organizations has been used to perform this research. Enzyme's Kinetics raw data were measured in independent tests inside the Biochemical Department of the University of Pisa. Both the source code and the compiled software are available freely for any user on GitHub. All measures, manipulations and exclusions of the data were reported. Sample size was determined before any data analysis.

\section{References}

[1] GraphPad Prism version 8.00 for Windows, GraphPad Software, La Jolla California USA, URL http://www.graphpad.com.

[2] Vasic-Racki, Durda \& Kragl, U \& Liese, Andreas. (2003). Benefits of Enzyme
Kinetics Modelling. Chem Biochem Eng

Q. 17.

[3] Michaelis L, Menten ML (1913) Kinetik der Invertinwirkung. Biochem Z 49: 333369.

[4] Motulsky, Harvey \& Ransnas, L.A.. (1987). Fitting Curves to Data Using Nonlinear Regression: A Practical and 
bioRxiv preprint doi: https://doi org/10.1101/674051; this version posted April 15,2020 . The copyright holder for this preprint (which was not certified by peer review) is the author/funder, who has granted bioRxiv a license to display the preprint in perpetuity. It is made available under aCC-BY 4.0 International license.

Nonmathematical Review. FASEB journal : official publication of the Federation of American Societies for Experimental Biology. 1. 365-74.

10.1096/fasebj.1.5.3315805.

[5] Eisenthal, R.S. \& Cornish-Bowden, Athel. (1974). The direct linear plot. A new graphical procedure for estimating enzyme kinetic parameters. The Biochemical journal. 139. 715-20. 10.1042/bj1390715.

[6] Arlan Ramsay, Robert D. Richtmyer, Introduction to hyperbolic geometry. $1^{\text {st }}$ ed. Springer-Verlag; 1991.

[7] W CLELAND, W. (1963). Computer Programmes for Processing Enzyme Kinetic Data. Nature. 198. 463-5. 10.1038/198463a0.
[8] R. Stifanese, D. L. Nelson \& M. M. Cox. I principi di biochimica di Lehninger. $6^{\text {th }}$ ed. Zanichelli; 2014.

[9] U. Mura. Enzimi in azione: Fondamenti di cinetica e regolazione delle funzioni

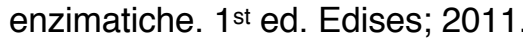

[10] R.A. Copeland. Enzymes. $2^{\text {nd }}$ ed. Wiley; 2000.

[11] A. Fersht, C .Bongarzoni. Struttura e meccanismi d'azione degli enzimi. $1^{\text {st }}$ ed. Zanichelli; 1989.

[12] R Development Core Team (2008). R: A language and environment for statistical computing. R Foundation for Statistical Computing,Vienna, Austria. ISBN 3900051-07-0, URL http://www.Rproject.org. 


\section{Supplementary Material:}

\section{Kinetics equations used from literature:}

Following it will be reported the main equations used by Easy Kinetics during the generation of several kinetic parameters once evaluated $\mathrm{V}_{\max }$ and $\mathrm{K}_{\mathrm{m}}$ values [6-10]:

$n H=\log _{[S]}\left(K_{m} * \frac{V_{0}}{V_{\max }-V_{0}}\right) \quad \begin{aligned} & \text { Equation used for the evaluation of the Hill } \\ & \text { coefficient }\end{aligned}$

$V_{0}=\frac{\operatorname{Vmax} *[S]^{n H}}{K m^{n H} *[S]^{n H}} \quad$ Equation used for the generation of the kinetic graph

$V_{0}=\frac{V \max *[S]^{n H}}{[S]^{n H} *\left(1+S_{i} *\left(\frac{[S]}{K_{i}}\right)^{n H}\right)+K m^{n H}} \quad \begin{aligned} & \text { Equation used for the evaluation of the } \mathrm{V}_{0} \text { at a set } \\ & \text { chosen substrate }\end{aligned}$

$V_{\text {moli }}=\frac{V_{0} * L_{f}}{O * \varepsilon} \quad \begin{aligned} & \text { Equation used to switch the previously evaluated } \mathrm{V}_{0}, \text { expressed in } \Delta \mathrm{Abs} / \mathrm{min} \text {, into } \\ & \text { a new } \mathrm{V}_{0} \text { value expressed in } \mu \text { moli of reporter product generated per minute }\end{aligned}$

$\mathrm{U}=\frac{A b s_{\text {high }}}{\left(\frac{L_{f}}{L_{i}}\right) * O * \varepsilon} \quad \begin{aligned} & \text { Equation used for the evaluation of the enzymatic units } \\ & \text { in the sample }\end{aligned}$ $C_{p}=\frac{\mathrm{Abs}_{\text {protein }}-\mathrm{Abs}_{\text {blank }}}{0.064 * 0} \quad \begin{aligned} & \text { Equation used for the evaluation of the protein } \\ & \text { concentration during the Bradford assay }\end{aligned}$

$S_{\text {activity }}=\frac{\mathrm{U}}{C_{p}} \quad \begin{aligned} & \text { Equation used for the evaluation of the enzyme's } \\ & \text { specific activity }\end{aligned}$

$K_{\text {cat }}=\frac{\mathrm{P} . \mathrm{M} * V_{\max }}{\varepsilon * O * C_{p}} \quad \begin{aligned} & \text { Equation used for the evaluation of the enzyme's } \\ & \mathrm{K}_{\mathrm{cat}}\end{aligned}$

$C_{\text {efficiency }}=\log _{10} \frac{K_{\text {cat }}}{K_{m}} \quad \begin{aligned} & \text { Equation used for the evaluation of the enzyme's } \\ & \text { catalytic efficiency }\end{aligned}$ 
where [S] represents the substrate's concentration; $S_{i}$ can be 1 , if substrate's inhibition is present or 0 , if substrate's inhibition is absent; $K_{i}$ represents the inhibition's constant evaluated at a very high substrate's concentration as:

$K_{i}=\frac{\left(100 * K_{m}\right)^{2}}{\frac{\left(100 * K_{m}\right) * V_{\max }}{A b s_{\left(100 * K_{m}\right)}-K_{m}-\left(100 * K_{m}\right)}}$

when substrate inhibition is present

$K_{i}=1$

when substrate inhibition is absent

$L_{f}$ represents the final volume of the sample; $L_{i}$ represents the starting volume of the sample; $\varepsilon$ represents the extinction molar coefficient of the product; $O$ represents the optical path of the spectrophotometer; Abshigh represents the absorbance measured at a very high substrate's concentration; Abs protein represents the absorbance of the protein's solution; Abs blank represents the absorbance measured for the previous solution without proteins inside; P.M. represents the molecular weight of the reporter product.

Enzyme's $\Delta \mathrm{Abs} / \mathrm{min}$ raw data for several concentrations of tested limiting substrates:

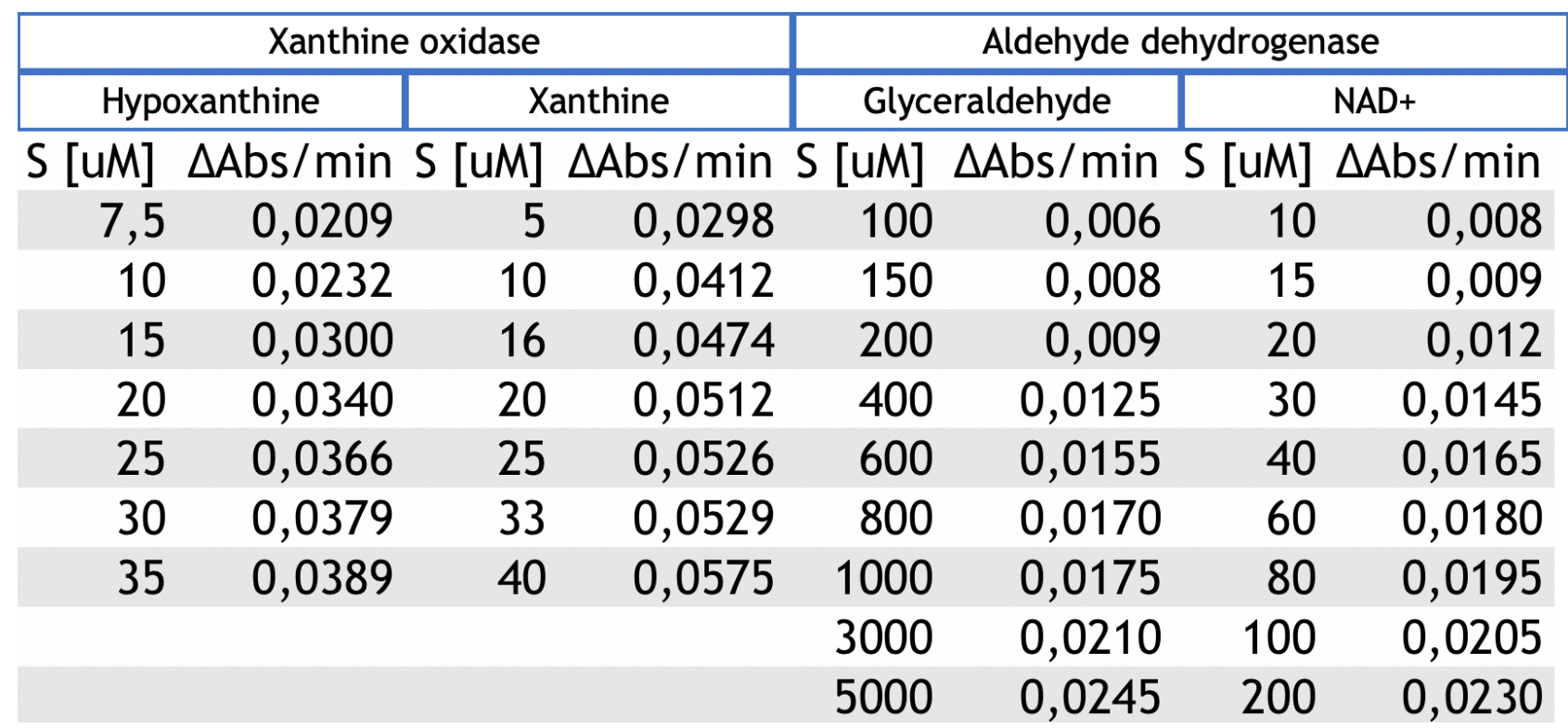

Tab.1: experimentally measured $\Delta \mathrm{Abs} / \mathrm{min}$ values for several substrate's concentrations in the enzyme's catalyzed reactions tested. 